\title{
STUDI POLA PERTUMBUHAN TANAMAN SAWI (Brassica rapa var. parachinensis L.) HIDROPONIK DI DALAM GREENHOUSE TERKONTROL
}

\author{
Plant Growth Pattern Study of Hydroponics Mustard (Brassica Rapa Var. Parachinensis L.) \\ in The Controlled Greenhouse
}

\author{
Mareli Telaumbanua', Bambang Purwantana', Lilik Sutiarso', Mohammad Affan Fajar Falah² \\ ${ }^{1}$ Jurusan Teknik Pertanian, Fakultas Teknologi Pertanian, Universitas Gadjah Mada, \\ Jl. Flora No. 1, Bulaksumur Yogyakarta 55281 \\ ${ }^{2}$ Jurusan Teknologi Industri Pertanian, Fakultas Teknologi Pertanian, Universitas Gadjah Mada, \\ Jl. Flora No. 1, Bulaksumur Yogyakarta 55281 \\ Email : marelitelaumbanua@gmail.com
}

\begin{abstract}
ABSTRAK
Tanaman sayuran harus dibudidayakan dengan optimal agar diperoleh hasil yang maksimal. Di wilayah tropis seperti di Indonesia, pertumbuhan tanaman sayuran dipengaruhi oleh beberapa faktor iklim seperti kelembaban, suhu, nutrisi dan cahaya. Untuk memperoleh kondisi yang optimal dan terkendali selama periode pertumbuhan, tanaman sawi dibudidayakan secara hidroponik di dalam greenhouse. Penelitian ini dilakukan untuk mengidentifikasi pola pertumbuhan tanaman sawi (Brassica rappa var. parachinensis L.) yang dibudidayakan secara hidroponik di dalam greenhouse yang dilengkapi dengan kendali suhu, nutrisi dan cahaya. Tujuan penelitian adalah menentukan kombinasi faktor terbaik yang memberikan pertumbuhan paling optimal. Penelitian dilakukan dengan memberikan tiga perlakuan dengan tiga variasi yaitu suhu $\left(32^{\circ} \mathrm{C}, 35^{\circ} \mathrm{C}\right.$, dan $\left.38^{\circ} \mathrm{C}\right)$, nutrisi $(2 \mathrm{mS} / \mathrm{cm}, 5 \mathrm{mS} / \mathrm{cm}$, dan $8 \mathrm{mS} / \mathrm{cm})$, dan cahaya $(7000$ lux, 12000 lux, dan 17000 lux) sehingga terdapat 27 ruang budidaya atau greenhouse dengan iklim mikro yang berbeda. Tingkat pertumbuhan ditentukan berdasarkan luas daun dan diukur selama 48 hari budidaya. Kendali di dalam masingmasing greenhouse dilakukan oleh aktuator pompa, lampu pijar dan lampu TL (Flourescent Lamp). Hasil penelitian menunjukkan suhu, nutrisi dan cahaya berpengaruh pada pertumbuhan tanaman sawi. Dari hasil analisis faktor tunggal, luas daun maksimum dihasilkan pada suhu $35^{\circ} \mathrm{C}$ yaitu $565 \mathrm{~cm}^{2}$, nutrisi $5 \mathrm{mS} / \mathrm{cm}$ yaitu $639,27 \mathrm{~cm}^{2}$ dan cahaya 17000 lux yaitu $697,42 \mathrm{~cm}^{2}$. Secara kombinasi, tingkat pertumbuhan terbaik diperoleh pada perlakuan suhu $35^{\circ} \mathrm{C}$, nutrisi 5 $\mathrm{mS} / \mathrm{cm}$, dan cahaya 17000 lux dengan hasil luas daun mencapai $1068,82 \mathrm{~cm}^{2}$.
\end{abstract}

Kata kunci: Cahaya, nutrisi, tanaman sawi, suhu

\begin{abstract}
The vegetables should be cultivated in an optimal way to obtain maximum yield. In tropical regions such in Indonesia, the growth of vegetables are influenced by climate factors such as humidity, temperature, nutrients and light. To gain the optimal and controlled condition during the growth periode, mustard plants could be cultivated hydroponically in a greenhouse. This study was conducted to identify the growth pattern of mustard (Brassica rappa var. Parachinensis L.) that hydroponically planted in a greenhouse which is equipped with a temperature, nutrients and light control. The aim of this research is to determine the best factors combination that provide the most optimum growth. This research was conducted by three treatments that were temperature, nutrition, and light. Each of the treatment has three variations : temperature $\left(32^{\circ} \mathrm{C}, 35^{\circ} \mathrm{C}\right.$, and $\left.38^{\circ} \mathrm{C}\right)$, nutrition $(2 \mathrm{mS} / \mathrm{cm}, 5 \mathrm{mS} / \mathrm{cm}$, and $8 \mathrm{mS} / \mathrm{cm})$, and light (7000 lux, 12000 lux, and 17000 lux) so there were 27 cultivation spaces or greenhouses used with different micro-climates. The growth rate was determined by the area of the leaf and it was measured during 48 days of cultivation. Control in each greenhouse is done by a pump actuator, incandescent bulbs and TL lamps. The result showed that temperature, nutrients and light affect on the growth of mustard. By single factor analysis, we found that maximum leaf area was produced at a temperature of $35^{\circ} \mathrm{C}$ that was $565 \mathrm{~cm}^{2}$, nutrition $5 \mathrm{mS} / \mathrm{cm}$ that was $639.27 \mathrm{~cm}^{2}$ and 17000 lux light that was $697.42 \mathrm{~cm}^{2}$. In short, the best growth rate was obtained at a temperature of $35^{\circ} \mathrm{C}$, nutrition of $5 \mathrm{mS} / \mathrm{cm}$, and 17000 lux of light yield 1068.82 $\mathrm{cm}^{2}$ of leaf area.
\end{abstract}

Keywords: Light, mustard plants, nutrition, temperature 


\section{PENDAHULUAN}

Tanaman untuk pangan harus dapat dibudidayakan dengan optimal dimanapun lokasi dan medianya. Dalam hal ini sistem hidroponik merupakan alternatif yang baik karena menggunakan media air, sehingga konsentrasi nutrisi relatif, distribusi nutrisi, lebih mudah dikontrol pada masa budidaya. Lokasi budidaya yang dipilih adalah rumah tanaman (greenhouse), karena rumah tanaman dapat melindungi tanaman dari pengaruh buruk faktor luar seperti angin kencang, hujan deras, hama dan lain sebagainya. Pengendalian iklim mikro di dalam rumah tanaman relatif lebih mudah untuk aplikasikan. Perawatan intensif dapat dilakukan agar kegagalan panen akibat iklim yang tidak stabil dapat diminimalkan.

Sawi hijau (Brassica rappa var. parachinensis L.) tergolong sayuran yang banyak dikonsumsi oleh penduduk Indonesia. Rasanya yang manis, dapat dijadikan manisan dan memiliki kandungan gizi yang tinggi merupakan kelebihannya. Namun demikian sayuran sawi peka terhadap perubahan lingkungan yang tidak sesuai dengan pertumbuhannya. Hal ini ditunjukkan langsung oleh perubahan fisik pada tanaman seperti daun menjadi layu (Opena dan Tay, 1994). Tanaman sawi membutuhkan perlakuan khusus seperti budidaya di dalam greenhouse yang pengendalian iklim yang sesuai untuk budidayanya agar diperoleh panen yang lebih baik. Penelitian ini menggunakan objek sayuran sawi hijau (Brassica rappa var. parachinensis L.) dengan pengamatan khusus pada luas keseluruhan luas daun. Hasil utama tanaman ini adalah daun yang dijadikan tingkat pertumbuhan tanaman.

Dalam budidaya di greenhouse, tanaman sawi membutuhkan kesesuaian iklim mikro berupa cahaya, suhu dan nutrisi agar pertumbuhan tanaman sawi dapat optimal. Pertumbuhan tanaman sawi maksimal jika didukung dengan dengan kondisi iklim yang paling sesuai. Untuk mengetahui pengaruh pertumbuhan sawi terhadap kondisi iklim yang berbeda, diperlukan penelitian tentang identifikasi pola pertumbuhan tanaman sawi terhadap suhu, nutrisi dan cahaya yang berbeda. Dengan penerapan teknologi otomatisasi pada sistem hidroponik di dalam greenhouse, proses budidaya dengan banyak variasi iklim mikro dapat dikendalikan.

Pola pertumbuhan setiap ruangan dengan perbedaan iklim mikro di dalamnya menunjukan luas daun yang berbeda. Hal ini dibuktikan oleh Nurshanti (2009) tentang pengaruh nutrisi terhadap pertumbuhan tanaman sawi. Selain itu, identifikasi tingkat pertumbuhan tanaman pernah dilakukan tentang identifikasi pertumbuhan tanaman kedelai (Glycine $\max \mathrm{L}$ ) dengan pengaruh pemberian komposisi nutrisi tanaman (Suyantohadi, dkk., 2009). Kandungan nutrisi untuk perkembangan luas daun, tinggi tanaman, panjang akar tanaman yang terbaik adalah nutrisi yang sesuai dengan massa dan usia tanaman. Kekurangan dan kelebihan nutrisi pada tanaman juga mempengaruhi pertumbuhan tanaman. (Hakim, dkk., 1986 ; Nyakpa, dkk., 1988 ; Buckman dan Brady, 1982). Selain kekurangan nutrisi, kekurangan cahaya juga mempengaruhi pertumbuhan tanaman (Phaisal, 2005; Widastuti, 2004). Penelitian tentang pengaruh cahaya dan suhu dilakukan Pertamawati (2010) terhadap tanaman kentang dengan melakukan variasi cahaya dan suhu selama masa budidaya. Hasil yang diperoleh adalah cahaya dan suhu yang lebih tinggi memiliki hasil produksi yang lebih baik. Sehingga faktor suhu, cahaya dan nutrisi memiliki keterikatan untuk pendukung pertumbuhan tanaman. Tujuan dari penelitian ini adalah mendapatkan pola pertumbuhan tanaman sawi yang ditanam di dalam greenhouse dengan sistem hidroponik dengan variasi suhu, cahaya dan nutrisi terkontrol. Dari hasil pra-penelitian faktor tunggal, suhu $35^{\circ} \mathrm{C}$, nutrisi $5 \mathrm{mS} / \mathrm{cm}$, dan cahaya 12000 lux adalah kondisi yang ideal untuk budidaya sawi. Berdasarkan hasil tersebut, pada penelitian ini dilakukan pengukuran perubahan luas daun terhadap penambahan variasi untuk mendapatkan kombinasi masing-masing faktor pertumbuhan yaitu suhu $32^{\circ} \mathrm{C}, 35^{\circ} \mathrm{C}$, $38^{\circ} \mathrm{C}$, nutrisi $2 \mathrm{mS} / \mathrm{cm}, 5 \mathrm{mS} / \mathrm{cm}, 8 \mathrm{mS} / \mathrm{cm}$, dan cahaya 7000 lux, 12000 lux dan 17000 lux. Faktor pertumbuhan tersebut dijadikan faktor input pertumbuhan. Masing-masing faktor ini divariasikan sebanyak tiga kali $(3 \times 3 \times 3)$ sehingga menghasilkan 27 variasi iklim mikro pada masing-masing greenhouse. Data yang tersedia digunakan untuk ditampilan dalam bentuk grafik. Data tersebut kemudian dianalisis sehingga diperoleh faktor tunggal masing-masing faktor pertumbuhan, terhadap perubahan luas daun. Hasil yang didapatkan dapat digunakan untuk pengambilan keputusan yang diharapkan dapat membantu petani maupun peneliti dalam mengembangkan dan meningkatkan hasil dari suatu komoditas pertanian terutama sayuran sawi.

\section{METODE PENELITIAN}

\section{Tempat, Bahan, dan Peralatan}

Penelitian ini akan dilaksanakan mulai dari Maret 2013 - Maret 2014 di Laboratorium Energi dan Mesin Pertanian, Jurusan Teknik Pertanian, Fakultas Teknologi Pertanian, Universitas Gadjah Mada, Yogyakarta.

Bahan yang digunakan dalam penelitian ini adalah pupuk hidroponik produksi Goodplant, bibit sawi hijau usia 3 minggu, pot penyangga, termometer, hygrometer, lux meter, EC meter. Bahan yang dipersiapkan untuk pembuatan greenhouse adalah besi lubang, baut, pipa paralon, steorofoam, gergaji, kabel dan seperangkat peralatan teknik. Pengendali iklim mikro adalah sistem kontrol antara aktuator mikrokontroler ATMega32. 


\section{Pelaksanaan Penelitian}

Tanaman yang telah dibibitkan selama 3 minggu dengan tinggi $10 \mathrm{~cm}$, dipindahkan ke greenhouse yang memiliki kondisi lingkungan yang terkontrol. Usia 3 minggu merupakan usia ideal. Tanaman sudah lebih besar dan memiliki perakaran yang baik, sehingga dianggap mampu untuk beradaptasi dengan lingkungan baru. Faktor pertumbuhan yang diamati adalah perubahan luas daun dari hari ke 0 hingga hari ke 48 atau panen. Pengamatan laju pertumbuhan luas daun dilakukan setiap 3 hari dengan cara mengukur luas setiap daun pada tanaman. Luas daun diukur dengan cara mengukur dimensi panjang dan lebar daun tanaman sawi yang berbentuk elips. Selanjutnya luas daun akan dihitung dengan penggunakan rumus elips dan dikali dengan faktor koreksi. Faktor koreksi diperoleh dari pengukuran planimeter pada berbagai jenis ukuran daun. Dalam 1 ruangan, terdapat 4 ulangan tanaman sawi. Data yang diperoleh dari pengamatan sejumlah 1836 luas daun mulai dari hari ke 0 hingga hari ke 48 dari 27 greenhouse. Seluruh data digunakan untuk identifikasi pola pertumbuhan tanaman setiap faktor.

Tanaman dibudidayakan di dalam greenhouse yang telah dirancang dengan mikrokontroler dan aktuator untuk mengendalikan lingkungan secara hidroponik, dengan kombinasi 3 faktor pertumbuhan yaitu suhu, cahaya, dan nutrisi yang masing-masing faktor memiliki 3 variasi dengan 4 ulangan tanaman (Tabel 1). Rincian kegiatan secara umum dijelaskan melalui Gambar 1.

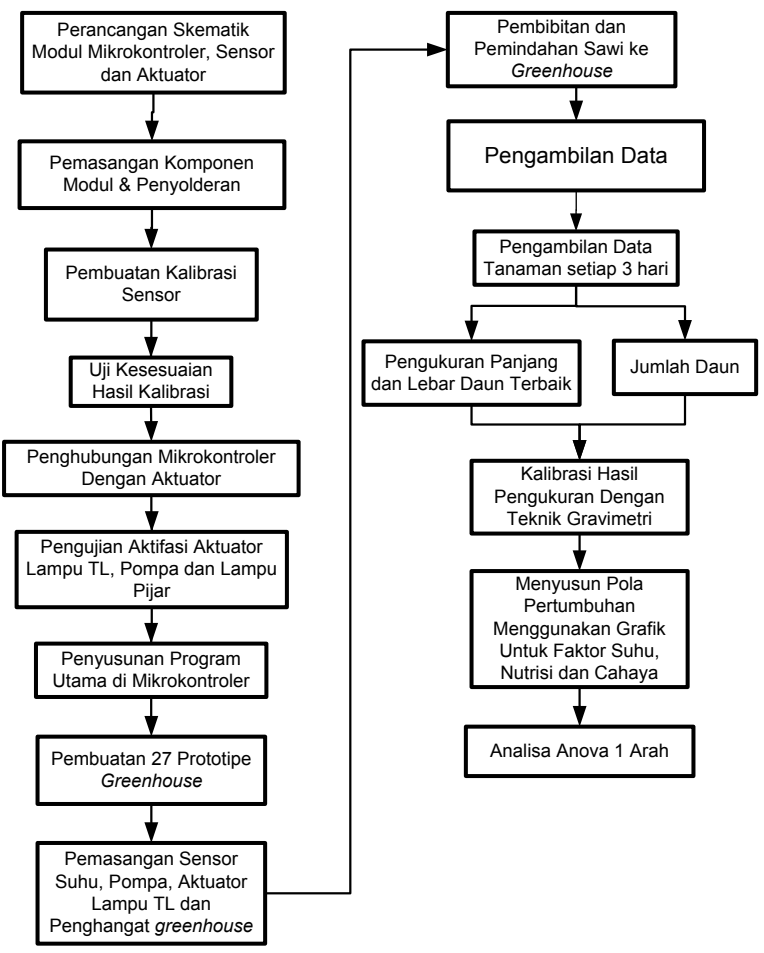

Gambar 1. Diagram alir identifikasi pola pertumbuhan
Tabel 1. Faktor iklim yang divariasikan

\begin{tabular}{lccc}
\hline \multicolumn{1}{c}{ Faktor iklim } & \multicolumn{3}{c}{ Variasi } \\
\hline Suhu (S1,S2,S3) & $32{ }^{\circ} \mathrm{C}$ & $35{ }^{\circ} \mathrm{C}$ & $38{ }^{\circ} \mathrm{C}$ \\
Nutrisi (N1,N2,N3) & $\pm 2 \mathrm{mS} / \mathrm{cm}$ & $\pm 5 \mathrm{mS} / \mathrm{cm}$ & $\pm 8 \mathrm{mS} / \mathrm{cm}$ \\
Lampu (L1,L2,L3) & $7000 \mathrm{Lux}$ & $12000 \mathrm{Lux}$ & $17000 \mathrm{Lux}$ \\
\hline
\end{tabular}

\section{Identifikasi Pola Pertumbuhan}

Identifikasi pola pertumbuhan dalam penelitian ini dengan melakukan penggabungan hasil rerata dua faktor yang berpengaruh. Hasil ini akan digunakan untuk mendapatkan rerata satu faktor pertumbuhan yang berpengaruh. Rancangan ini merupakan penguraian dari analisis faktorial yang ditujukan untuk mempermudah analisis untuk melihat masing-masing pengaruh dari masing-masing faktor pertumbuhan.

Tabel 2. Tabel kombinasi untuk mencari pengaruh tunggal

\begin{tabular}{ccc}
\hline \multicolumn{3}{c}{ Mencari pengaruh tunggal } \\
\hline Faktor utama & Faktor rerata & Faktor konstan \\
\hline Nutrisi $8,2,5(\mathrm{mS} / \mathrm{cm})$ & Cahaya A,B,C $($ lux $)$ & Suhu $32\left({ }^{\circ} \mathrm{C}\right)$ \\
Nutrisi $8,2,5(\mathrm{mS} / \mathrm{cm})$ & Cahaya A,B,C $($ lux $)$ & Suhu $35\left({ }^{\circ} \mathrm{C}\right)$ \\
Nutrisi $8,2,5(\mathrm{mS} / \mathrm{cm})$ & Cahaya A,B,C $(\mathrm{lux})$ & Suhu $38\left({ }^{\circ} \mathrm{C}\right)$ \\
Cahaya A,B,C $($ lux $)$ & Suhu 32,35,38 $\left({ }^{\circ} \mathrm{C}\right)$ & Nutrisi $8(\mathrm{mS} / \mathrm{cm})$ \\
Cahaya A,B,C $($ lux $)$ & Suhu 32,35,38 $\left({ }^{\circ} \mathrm{C}\right)$ & Nutrisi $2(\mathrm{mS} / \mathrm{cm})$ \\
Cahaya A,B,C $($ lux $)$ & Suhu 32,35,38 $\left({ }^{\circ} \mathrm{C}\right)$ & Nutrisi $5(\mathrm{mS} / \mathrm{cm})$ \\
Suhu 32,35,38 $\left({ }^{\circ} \mathrm{C}\right)$ & Nutrisi $8,2,5(\mathrm{mS} / \mathrm{cm})$ & Cahaya A $(\mathrm{lux})$ \\
Suhu 32,35,38 $\left({ }^{\circ} \mathrm{C}\right)$ & Nutrisi $8,2,5(\mathrm{mS} / \mathrm{cm})$ & Cahaya B $(\mathrm{lux})$ \\
Suhu 32,35,38 $\left({ }^{\circ} \mathrm{C}\right)$ & Nutrisi $8,2,5(\mathrm{mS} / \mathrm{cm})$ & Cahaya C $(\operatorname{lux})$ \\
\hline
\end{tabular}

Keterangan: Cahaya A,B,C berturut-turut adalah 7000 lux, 12000 lux dan 17000 lux.

Sebagai contoh untuk mengukur faktor tunggal suhu, langkah pertama adalah melakukan perhitungan dan membuat grafik 32,35 , dan $38^{\circ} \mathrm{C}$ (lihat baris 1-3, tabel 2). Perhitungan grafik $32{ }^{\circ} \mathrm{C}$ pada baris satu, diawali dengan merata-ratakan hasil nutrisi 8,5,2 $\mathrm{mS} / \mathrm{cm}$ (lihat kolom faktor utama, tabel 2), pada cahaya A (lihat kolom faktor rerata, tabel 2) pada suhu $32{ }^{\circ} \mathrm{C}$ (lihat kolom faktor konstan, tabel 2) seluruh data pengamatan 48 hari. Kemudian tampilkan dalam grafik yaitu pengaruh nutrisi $8,5,2 \mathrm{mS} / \mathrm{cm}$ pada suhu $32{ }^{\circ} \mathrm{C}$ cahaya A,B,C. Reratakan hasil nutrisi $8,5,2 \mathrm{mS} / \mathrm{cm}$ pada cahaya B, pada suhu $32{ }^{\circ} \mathrm{C}$ (lihat baris ke dua pada tabel 2). Hasilnya tampilkan juga diikut sertakan di dalam grafik yang sama. Demikian juga halnya pada rerata nutrisi $8,5,2 \mathrm{mS} / \mathrm{cm}$, cahaya $\mathrm{C}$ dengan suhu $32{ }^{\circ} \mathrm{C}$. Hasil nya ditampilkan dalam grafik ke 1. Pada grafik satu akan muncul garis pertama yaitu variasi rerata nutrisi $8,5,2 \mathrm{mS} / \mathrm{cm}$ pada cahaya $A$, garis ke dua yaitu variasi rerata nutrisi $8,5,2 \mathrm{mS} / \mathrm{cm}$ pada cahaya $B$ dan garis ke tiga yaitu variasi rerata nutrisi $8,5,2 \mathrm{mS} / \mathrm{cm}$ pada 
cahaya $\mathrm{C}$ pada suhu $32{ }^{\circ} \mathrm{C}$ (lihat gambar ke 2). Kemudian hasil 3 garis ini dirata-ratakan, sehingga disebut pengaruh faktor pertumbuhan pada suhu $32^{\circ} \mathrm{C}$. Perhitungan yang sama kemudian dilakukan untuk mendapatkan data pengaruh pada suhu $35^{\circ} \mathrm{C}$ dan $38^{\circ} \mathrm{C}$ (baris 2-3, tabel 2). Data pengaruh suhu 32,35 , dan $38^{\circ} \mathrm{C}$ ditampilkan dalam grafik scatter dan grafik column untuk mempermudah pembacaan. Cara ini digunakan untuk menghitung pengaruh nutrisi, dan pengaruh cahaya pada pertumbuhan tanaman sawi. Hasil identifikasi pola pertumbuhan tanaman sawi berupa luas daun tanaman setiap faktor, dengan cara mengukur selisih titik puncak tertinggi luas daun pada masing-masing faktor.

\section{HASIL DAN PEMBAHASAN}

\section{Pengaruh Suhu terhadap Pertumbuhan Tanaman Sawi di Greenhouse}

Suhu merupakan faktor penting di dalam proses fotosintesis untuk pertumbuhan tanaman. Suhu memberikan energi pada tanaman agar tanaman dapat melaksanakan proses-proses fisiologisnya, mempengaruhi produk sintesa, evapotranspirasi daun dan metabolisme tanaman.

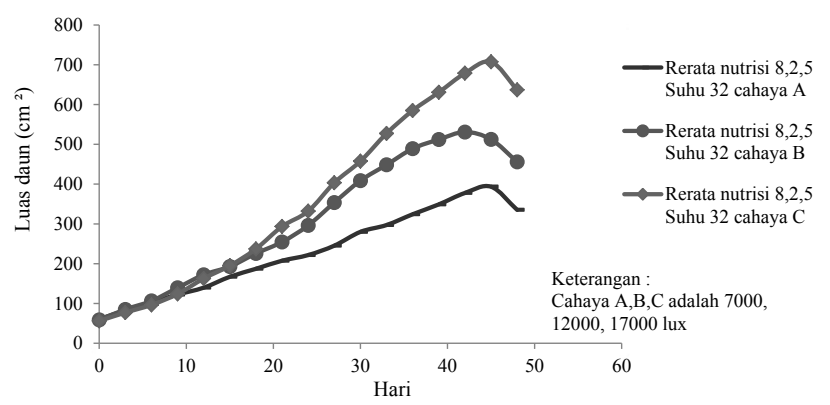

Gambar 2. Pengaruh nutrisi dan cahaya pada suhu $32{ }^{\circ} \mathrm{C}$

Pengaruh laju pertumbuhan pada Gambar 2 menunjukkan, luas daun maksimal $707,31 \mathrm{~cm}^{2}$ dari cahaya 17000 lux pada suhu $32{ }^{\circ} \mathrm{C}$. Sedangkan cahaya 12000 lux dengan luas daun $530,91 \mathrm{~cm}^{2}$ dan cahaya 7000 lux dengan luas daun $393,46 \mathrm{~cm}^{2}$.

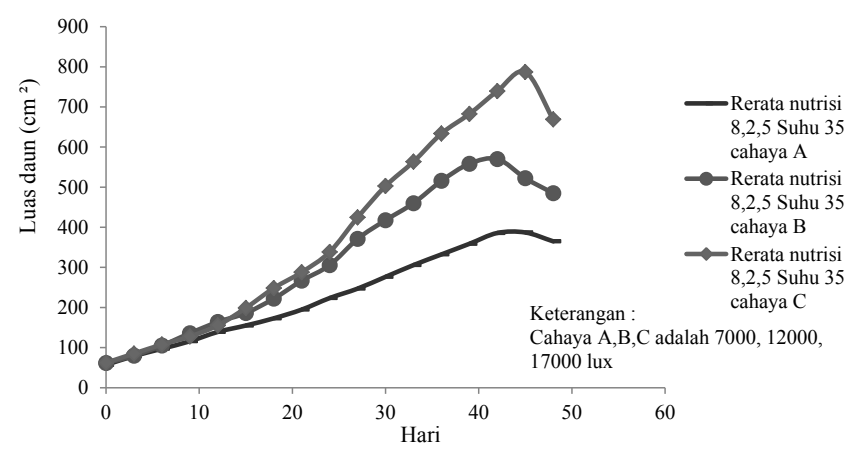

Gambar 3. Pengaruh nutrisi dan cahaya pada suhu $35^{\circ} \mathrm{C}$
Pengaruh laju pertumbuhan pada Gambar 3 menunjukkan suhu $35{ }^{\circ} \mathrm{C}$, cahaya 17000 lux dengan luas daun maksimal 787,01 $\mathrm{cm}^{2}$. Cahaya 12000 lux dengan luas daun 570,08 lux dan pada cahaya 7000 lux, luas daun yang diperoleh adalah $386,97 \mathrm{~cm}^{2}$.

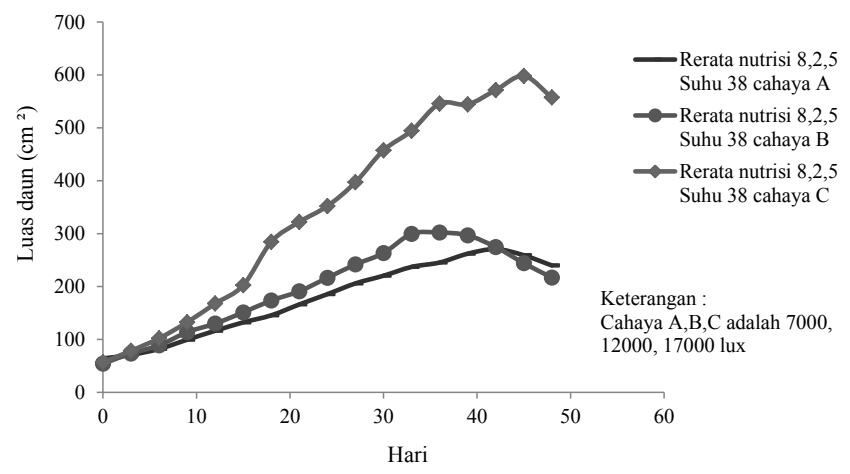

Gambar 4. Pengaruh nutrisi dan cahaya pada suhu $38^{\circ} \mathrm{C}$

Pengaruh laju pertumbuhan pada Gambar 4 menunjukkan bahwa cahaya 17000 lux memiliki luas daun maksimal 597,94 $\mathrm{cm}^{2}$. Cahaya 12000 lux dengan luas daun $302,1 \mathrm{~cm}^{2}$ dan cahaya 7000 lux, dengan luas daun $270,69 \mathrm{~cm}^{2}$.

Tabel 3. Hasil analisis anova terhadap pengaruh suhu

\begin{tabular}{lllll}
\hline Suhu & Persamaan garis kuadratis & $\mathrm{R}^{2}$ & F-Hitung & F-Tabel \\
\hline $32{ }^{\circ} \mathrm{C}$ & $\mathrm{y}=-14,588 \mathrm{x}^{2}+202,19 \mathrm{x}-155,51$ & 0,9766 & & \\
$35^{\circ} \mathrm{C}$ & $\mathrm{y}=-15,643 \mathrm{x}^{2}+217,43 \mathrm{x}-176,89$ & 0,9695 & 12,2115 & 4,256495 \\
$38^{\circ} \mathrm{C}$ & $\mathrm{y}=-14,14 \mathrm{x}^{2}+167,06 \mathrm{x}-111,25$ & 0,9757 & & \\
\hline
\end{tabular}

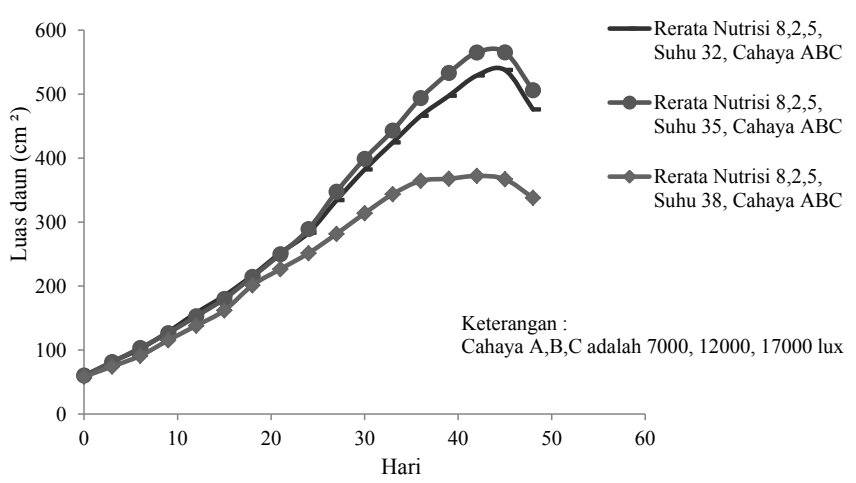

Gambar 5. Perubahan laju pertumbuhan oleh pengaruh suhu

Tingkat pertumbuhan pada Gambar 5 menunjukkan bahwa pertumbuhan terbaik pada suhu $35{ }^{\circ} \mathrm{C}$ dengan luas daun maksimal $565,41 \mathrm{~cm}^{2}$. Suhu $32{ }^{\circ} \mathrm{C}$ dengan luas daun $537,72 \mathrm{~cm}^{2}$ dan suhu $38{ }^{\circ} \mathrm{C}$ luas daun yang diperoleh adalah $372,18 \mathrm{~cm}^{2}$. Hasil analisis Anova satu arah dari slope fungsi linear setiap ulangan terhadap pengaruh suhu pada tabel 3 menunjukkan $\mathrm{H} 0 \neq \mathrm{H} 1$, T-hitung $>$ T-tabel. Hasil ini 
menunjukkan perbedaan antara masing-masing suhu dalam budidaya sawi dengan probabilitas 0,05 . Perbedaan terdapat pada suhu $32^{\circ} \mathrm{C}, 35^{\circ} \mathrm{C}$ dengan $38^{\circ} \mathrm{C}$, sedangkan kan $32^{\circ} \mathrm{C}$ dengan $35^{\circ} \mathrm{C}$ tidak tampak beda nyata. Persamaan kuadratis dalam tabel 3 merupakan pola pertumbuhan tanaman.

\section{Pengaruh Cahaya terhadap Pertumbuhan Tanaman Sawi di Greenhouse}

Cahaya sangat bermanfaat bagi tumbuhan karena perannya dalam kegiatan fisiologis seperti pembentukan krolofil respirasi, pembukaan, penutupan stomata, perkecambahan dan pertumbuhan tanaman. Penyinaran matahari mempengaruhi pertumbuhan, reproduksi dan hasil tanaman melalui proses fotosintesis.

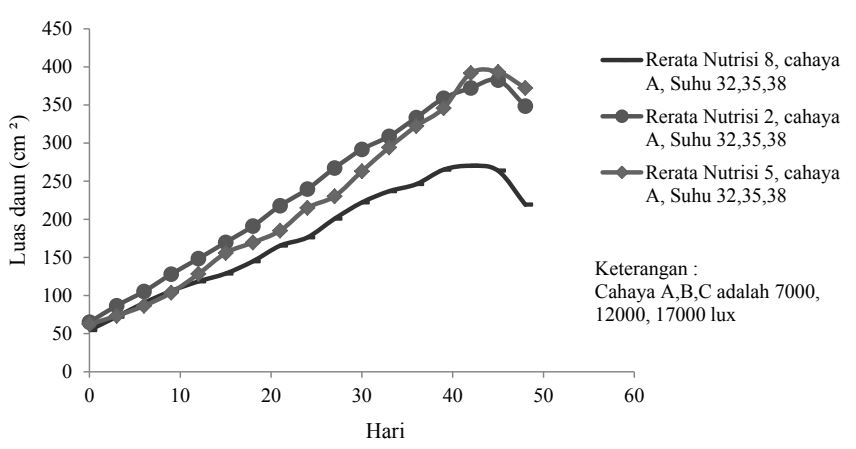

Gambar 6. Pengaruh suhu dan nutrisi pada cahaya 7000 lux

Pengaruh laju pertumbuhan pada Gambar 6 menunjukkan bahwa pencahayaan 7000 lux pada nutrisi 5 $\mathrm{mS} / \mathrm{cm}$ dengan luas daun 393,25 $\mathrm{cm}^{2}$. Nutrisi $8 \mathrm{mS} / \mathrm{cm}$ luas daun tanaman yang diperoleh $382,61 \mathrm{~cm}^{2}$ dan nutrisi $2 \mathrm{mS} /$ $\mathrm{cm}$, luas daun yang diperoleh $270,19 \mathrm{~cm}^{2}$.

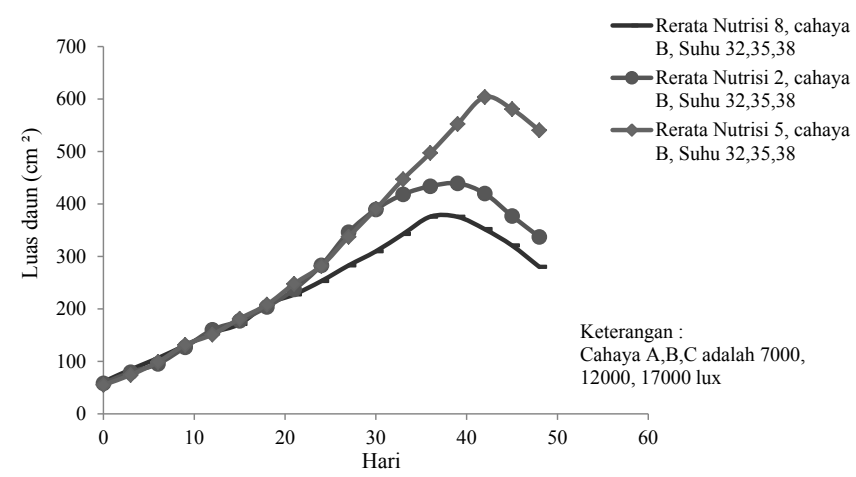

Gambar 7. Pengaruh suhu dan nutrisi pada cahaya 12000 lux

Pengaruh laju pertumbuhan pada Gambar 7 menunjukkan pencahayaan 12000 lux pada nutrisi $5 \mathrm{mS} / \mathrm{cm}$ diperoleh luas daun $603,78 \mathrm{~cm}^{2}$. Nutrisi $8 \mathrm{mS} / \mathrm{cm}$ diperoleh $439,33 \mathrm{~cm}^{2}$ dan pada nutrisi $2 \mathrm{mS} / \mathrm{cm}$, diperoleh $375,81 \mathrm{~cm}^{2}$.

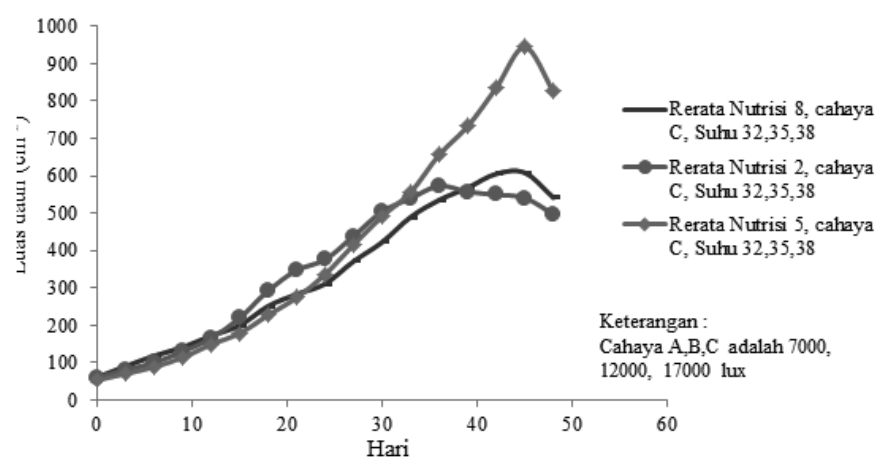

Gambar 8. Pengaruh suhu dan nutrisi pada cahaya 17000 lux

Pengaruh laju pertumbuhan pada Gambar 8 menunjukkan pencahayaan 17000 lux pada nutrisi $5 \mathrm{mS} / \mathrm{cm}$ diperoleh luas daun $943,82 \mathrm{~cm}^{2}$. Nutrisi $8 \mathrm{mS} / \mathrm{cm}$ diperoleh luas $607,88 \mathrm{~cm}^{2}$ dan nutrisi $2 \mathrm{mS} / \mathrm{cm}$ diperoleh luas 572,93 $\mathrm{cm}^{2}$.

Tabel 4. Hasil analisis anova terhadap pengaruh cahaya

\begin{tabular}{lllll}
\hline Cahaya & Persamaan garis kuadratis & $R^{2}$ & F-Hitung & F-Tabel \\
\hline 7000 Lux & $y=-9,1348 x^{2}+122,95 x-63,705$ & 0,971 & & \\
12000 Lux & $y=-17,928 x^{2}+211,05 x-162,4$ & 0,9756 & 93,4548 & 4,256495 \\
17000 Lux & $y=-17,308 x^{2}+252,68 x-217,55$ & 0,9748 & & \\
\hline
\end{tabular}

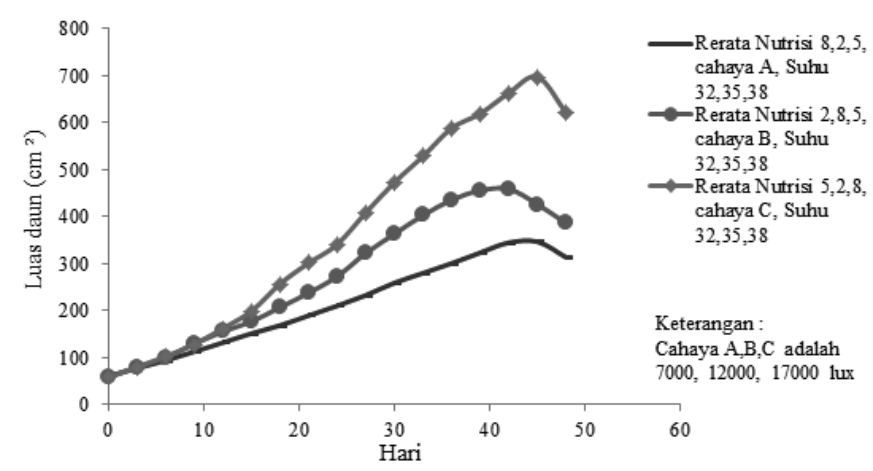

Gambar 9. Perubahan laju pertumbuhan oleh pengaruh cahaya

Tingkat pertumbuhan pada Gambar 9 menunjukkan bahwa pertumbuhan terbaik pada cahaya 17000 dengan luas daun maksimal 697,42 cm. Cahaya 7000 lux diperoleh $346,53 \mathrm{~cm}^{2}$ dan cahaya 12000 lux diperoleh 458,52 $\mathrm{cm}^{2}$. Hasil analisis anova satu arah pada setiap ulangan dengan probabilitas 0,05 terhadap pengaruh cahaya pada tabel 4 menunjukan $\mathrm{H} 0 \neq \mathrm{H} 1$, T-Hitung $>$ T-tabel sehingga terdapat perbedaan antara masing-masing perlakuan variasi cahaya dalam budidaya sawi. Percobaan dengan variasi cahaya menghasilkan perbedaan nyata antar hasilnya yang diperoleh.

Saat ini penelitian tentang pengaruh antara cahaya, suhu, dan nutrisi yang telah dilakukan, masih terbatas pada 1-2 faktor seperti yang dilakukan Harwati (2008), tentang 
pengaruh panjang penyinaran dan suhu terhadap umbi kentang. Keterbatasan kemampuan dalam perancangan sistem pengendali dipadu dengan pengetahuan tentang tanaman, menjadikan penelitian dengan 3 faktor iklim secara bersamaan menjadi lebih sulit. Keterbatasan dalam penelitian ini adalah, perancangan perangkat pengendali cahaya masih kurang tinggi dibandingkan cahaya matahari pada saat siang tanpa awan, yang mencapai 100000 lux. Permasalahan ke depan yang menjadi tantangan bagi peneliti lainnya dan pengembangan IPTEK adalah diperlukan desain lampu, led atau kombinasi lampu-led yang memiliki kemampuan untuk melampaui intensitas yang disediakan oleh cahaya matahari. Jika ada beberapa jenis led dengan intensitas tinggi, tentu harga yang dimiliki sangat mahal. Dengan adanya variasi cahaya yang melebihi cahaya sinar matahari, akan membuka pengetahuan baru tentang pengaruh cahaya, jika tanaman diberi cahaya melebihi kemampuannya.

\section{Pengaruh Nutrisi terhadap Pertumbuhan Tanaman Sawi di Greenhouse}

Nutrisi merupakan hal yang penting bagi tanaman. Hal ini berfungsi sebagai makanan bagi tanaman untuk diubah menjadi energi dan menambah massa tanaman selama masa hidupnya.

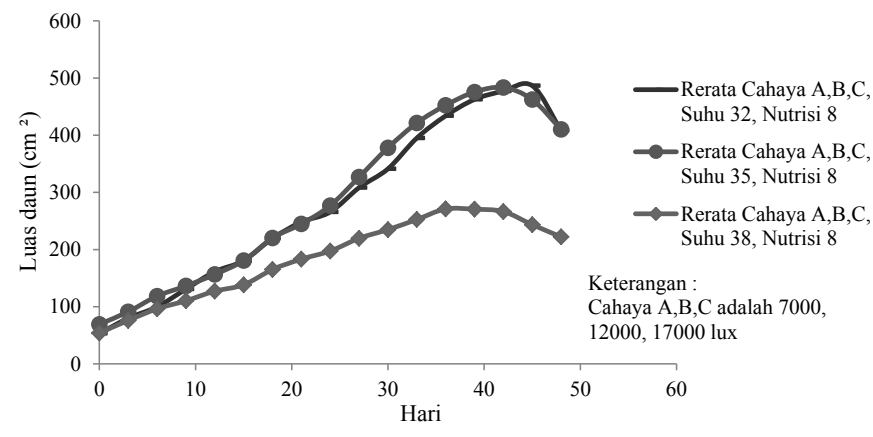

Gambar 10. Pengaruh cahaya dan suhu pada nutrisi $8 \mathrm{mS} / \mathrm{cm}$

Pengaruh laju pertumbuhan nutrisi 8 pada Gambar 10 menunjukkan pertumbuhan terbaik pada suhu $32{ }^{\circ} \mathrm{C}$ dengan luas daun 486,62 $\mathrm{cm}^{2}$. Suhu $35^{\circ} \mathrm{C}$ diperoleh $483,43 \mathrm{~cm}^{2}$ dan pada suhu $38^{\circ} \mathrm{C}$, diperoleh adalah $271 \mathrm{~cm}^{2}$.

Pengaruh laju pertumbuhan nutrisi $5 \mathrm{mS} / \mathrm{cm}$ pada Gambar 11 menunjukkan bahwa pertumbuhan terbaik pada suhu $35{ }^{\circ} \mathrm{C}$ dengan luas daun maksimal $728,11 \mathrm{~cm}^{2}$. Suhu 32 ${ }^{\circ} \mathrm{C}$ luas daun tanaman yang diperoleh $645,2 \mathrm{~cm}^{2}$ dan suhu 38 ${ }^{\circ} \mathrm{C}$, diperoleh 544,5 $\mathrm{cm}^{2}$.

Pengaruh laju pertumbuhan nutrisi $2 \mathrm{mS} / \mathrm{cm}$ pada Gambar 12 menunjukkan bahwa pertumbuhan terbaik pada suhu $32{ }^{\circ} \mathrm{C}$ dengan luas daun $505,78 \mathrm{~cm}^{2}$, tetapi pada suhu $32{ }^{\circ} \mathrm{C}$, luas permukaan daun adalah $504,42 \mathrm{~cm}^{2}$. Hal ini

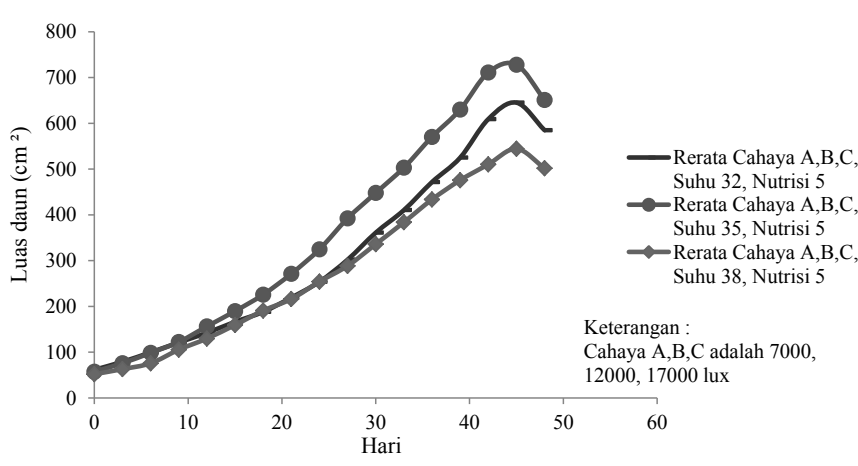

Gambar 11. Pengaruh cahaya dan suhu pada nutrisi $5 \mathrm{mS} / \mathrm{cm}$

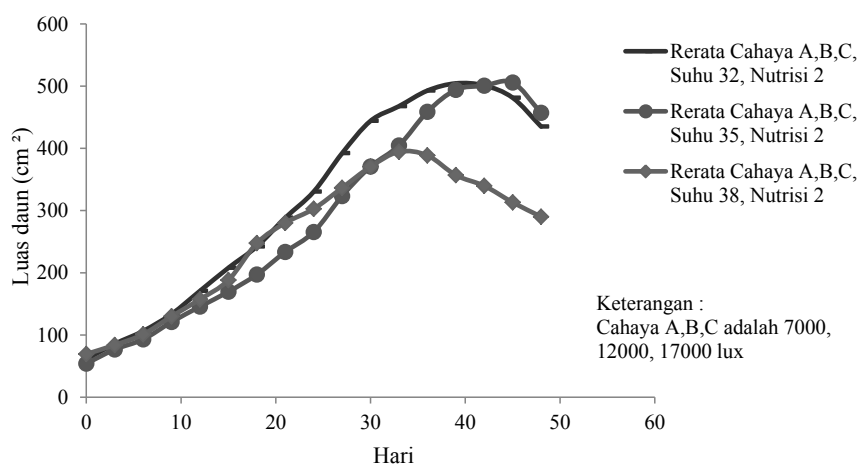

Gambar 12. Pengaruh cahaya dan suhu pada nutrisi $2 \mathrm{mS} / \mathrm{cm}$

menunjukkan bahwa budidaya pada suhu $32{ }^{\circ} \mathrm{C}$ dan $35^{\circ} \mathrm{C}$ nutrisi $2 \mathrm{mS} / \mathrm{cm}$ dengan cahaya 17000 lux, menghasilkan pertumbuhan luas daun yang hampir sama, walaupun suhu $32{ }^{\circ} \mathrm{C}$ menunjukkan laju pertumbuhan yang lebih cepat. Sedangkan luas permukaan daun pada suhu $38^{\circ} \mathrm{C}$ adalah $394,5 \mathrm{~cm}^{2}$.

Tabel 5. Hasil analisis anova terhadap pengaruh nutrisi

\begin{tabular}{lllll}
\hline Nutrisi & Persamaan garis kuadratis & $\mathrm{R}^{2}$ & F-Hitung & F-Tabel \\
\hline $2 \mathrm{mS} / \mathrm{cm}$ & $\mathrm{Y}=-18,648 \mathrm{x}^{2}+215,13 \mathrm{x}-159,26$ & 0,971 & & \\
$5 \mathrm{mS} / \mathrm{cm}$ & $\mathrm{y}=-11,316 \mathrm{x}^{2}+195,82 \mathrm{x}-162,33$ & 0,9756 & 29,34319872 & 4,256494729 \\
$8 \mathrm{mS} / \mathrm{cm}$ & $\mathrm{y}=-14,406 \mathrm{x}^{2}+175,73 \mathrm{x}-122,06$ & 0,9748 & & \\
\hline
\end{tabular}

Tingkat pertumbuhan pada Gambar 13 menunjukkan bahwa pertumbuhan terbaik pada nutrisi $5 \mathrm{mS} / \mathrm{cm}$ dengan luas daun maksimal 639,27 $\mathrm{cm}^{2}$. Sedangkan pada nutrisi 2 $\mathrm{mS} / \mathrm{cm}$ luas daun tanaman yang diperoleh adalah $451,78 \mathrm{~cm}^{2}$ dan pada nutrisi $8 \mathrm{mS} / \mathrm{cm}$, luas daun yang diperoleh adalah $409,05 \mathrm{~cm}^{2}$. Hal ini menunjukkan bahwa nutrisi terbaik untuk pertumbuhan tanaman adalah $5 \mathrm{mS} / \mathrm{cm}$. Terdapat perbedaan hasil pada penggunaan nutrisi $2 \mathrm{mS} / \mathrm{cm}$ dan $8 \mathrm{mS} /$ $\mathrm{cm}$ terhadap nutrisi 5 , sedangkan nutrisi $2 \mathrm{mS} / \mathrm{cm}$ terhadap nutrisi $8 \mathrm{mS} / \mathrm{cm}$ tidak tampak beda nyata. Kombinasi antara suhu $35^{\circ} \mathrm{C}$, nutrisi $5 \mathrm{mS} / \mathrm{cm}$ dengan cahaya 17000 


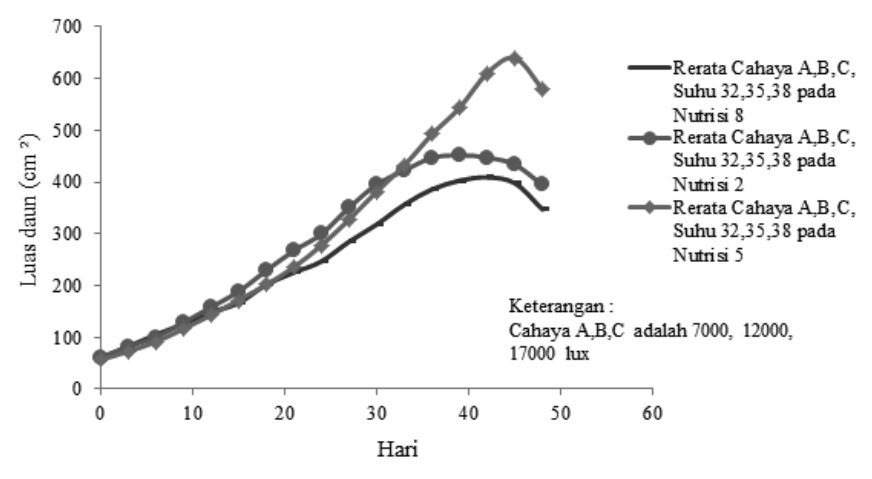

Gambar 13. Perubahan laju pertumbuhan oleh pengaruh nutrisi

lux, merupakan kombinasi terbaik dalam budidaya tanaman sawi di greenhouse dengan sistem hidroponik dengan luas permukaan daun $1068,83 \mathrm{~cm}^{2}$, sedangkan kombinasi terburuk bagi pertumbuhan dalam penelitian ini adalah cahaya 7000 lux, suhu $38{ }^{\circ} \mathrm{C}$, nutrisi $8 \mathrm{mS} / \mathrm{cm}$ dengan luas maksimal $201,71 \mathrm{~cm}^{2}$. Hasil analisis anova satu arah Tabel 5 untuk setiap ulangan percobaan, dengan probabilitas 0,05 terhadap pengaruh cahaya menunjukan $\mathrm{H} 0 \neq \mathrm{H} 1$, T-hitung $>$ T-tabel sehingga terdapat perbedaan antara masing-masing perlakuan variasi nutrisi dalam budidaya sawi.

\section{KESIMPULAN}

Berdasarkan hasil penelitian, identifikasi pola pertumbuhan tanaman sawi menunjukkan bahwa faktor lingkungan yaitu suhu, cahaya dan nutrisi saling memberikan pengaruh dalam pertumbuhan tanaman. Pengaruh suhu pada pertumbuhan luas daun sawi yang terbaik adalah suhu $35^{\circ} \mathrm{C}$ yaitu $565,41 \mathrm{~cm}^{2}$, sedangkan pada suhu $32{ }^{\circ} \mathrm{C}$ adalah 537,72 $\mathrm{cm}^{2}$, dan pada suhu $38{ }^{\circ} \mathrm{C}$ adalah $372,18 \mathrm{~cm}^{2}$. Pengaruh cahaya terbaik adalah 17000 lux dengan luas daun 697,42 $\mathrm{cm}^{2}$, sedangkan pada cahaya 7000 lux luas daun tanaman yang diperoleh adalah $346,53 \mathrm{~cm}^{2}$, dan cahaya 12000 lux diperoleh luas daun $458,52 \mathrm{~cm}^{2}$. Pengaruh nutrisi terbaik adalah 5 $\mathrm{mS} / \mathrm{cm}$ dengan luas daun maksimal $639,27 \mathrm{~cm}^{2}$, sedangkan pada nutrisi $2 \mathrm{mS} / \mathrm{cm}$ diperoleh $451,78 \mathrm{~cm}^{2}$, dan nutrisi 8 $\mathrm{mS} / \mathrm{cm}$ luas daun yang diperoleh $409,05 \mathrm{~cm}^{2}$. Kombinasi untuk pertumbuhan terbaik dalam penelitian adalah suhu 35 ${ }^{\circ} \mathrm{C}$, nutrisi $5 \mathrm{mS} / \mathrm{cm}$ dengan cahaya 17000 lux, dengan luas permukaan daun $1068,83 \mathrm{~cm}^{2}$, sedangkan kombinasi untuk tingkat pertumbuhan terendah adalah cahaya 7000 lux, suhu $38^{\circ} \mathrm{C}$, nutrisi $8 \mathrm{mS}$ dengan luas maksimal $201,71 \mathrm{~cm}^{2}$.

\section{DAFTAR PUSTAKA}

Buckman, H.O. dan Brady, N.C. (1982). Ilmu Tanah. Penerbit Bhratara Karya Aksara, Jakarta.

Hakim, N., Nyakpa, Y., Lubis, A., Nugroho, S., Saul, M., Diha, M.A., Hong, G.B. dan Bailey, H. (1986). Dasar-Dasar Ilmu Tanah. Universitas Lampung Press, Lampung.

Harwati, T.C. (2008). Pengaruh suhu dan panjang penyinaran terhadap umbi kentang (Solanum Tuberosum L.) Inovasi Pertanian 7: 11-8.

Opena, R.T. dan Tay, D.C.S. (1994). Brassica rappa L. Group Caisim. Plant resource of South-East Asia, Vegetable. Prosea Foundation. Hal : 153-157.

Pertamawati (2010). The responses of potatoes (Solanum Tuberosum L.) explant in vitro growth in photoautorof condition. Jurnal Sains dan Teknologi Indonesia 12: 31-37.

Phaisal, R. (2005). Pengaruh Naungan dan Pupuk Daun terhadap Pertumbuhan dan Produksi Seledri (Apium graveolens) dalam Teknologi Hidroponik Sistem Terapung (THST). Departemen Budidaya Perairan. Institut Pertanian Bogor, Bogor.

Nurshanti, D.F. (2009). Pengaruh pemberian pupuk organik terhadap pertumbuhan dan hasil tanaman sawi caisim (Brassica Juncea L.). Agronobis 1:1-9.

Nyakpa, M.Y., Lubis, A.M., Pulung, M., Amrah, A., Munawar, A., Hong, G.B. dan Hakim, N. (1988). Kesuburan Tanah. Universitas Lampung Press, Lampung.

Suyantohadi, A., Hariadi, M. dan Purnomo, M.H. (2009). Identifikasi pertumbuhan tanaman kedelai (Glycine $\max \mathrm{L}$ ) dengan pengaruh pemberian komposisi pupuk menggunakan metode artificial neural network. Agritech 29: 219-227.

Widiastuti, L. (2004). Pengaruh intensitas cahaya dan kadar daminosida terhadap iklim mikro dan pertumbuhan tanaman krisan dalam pot. Jurnal Ilmu Pertanian 11: 35-42. 